\title{
Effects of Infection by Mycosphaerella graminicola on Translocation of Fluquinconazole in Wheat Seedlings
}

\author{
Richard J. Metcalfe, Michael W. Shaw, and Philip E. Russell
}

First and second authors: University of Reading, Department of Agricultural Botany, 2 Earley Gate, Whiteknights, Reading RG6 6AU,

U.K.; and third author: AgrEvo U.K. Limited, Chesterford Park, Saffron Walden, Essex CB10 1XL, U.K.

Accepted for publication 23 June 2000.

\begin{abstract}
Metcalfe, R. J., Shaw, M. W., and Russell, P. E. 2000. Effects of infection by Mycosphaerella graminicola on translocation of fluquinconazole in wheat seedlings. Phytopathology 90:1345-1351.

Translocation of ${ }^{14} \mathrm{C}$-labeled fluquinconazole was measured using combustion analysis and radio thin-layer-chromatographic analysis in seedling wheat leaves uninfected and infected with Mycosphaerella graminicola. Two isolates were used with differing sensitivity to demethylation inhibitor fungicides. Fluquinconazole was translocated acro-

petally, but not basipetally. Fluquinconazole accumulated around infection sites within 6 days after treatment. Accumulation occurred before $M$. graminicola hyphae had colonized the host mesophyll further than one host cell around the invasion site. This suggested that the accumulation was caused by a host response to infection. Infrared gas analysis showed that rates of transpiration and stomatal conductance in inoculated leaves were significantly increased very soon after inoculation but net photosynthesis was decreased. The actual mechanism of fungicide accumulation was not determined.
\end{abstract}

Sterol $14 \alpha$ demethylation inhibitor (DMI) fungicides vary in their level of systemicity $(4,10,15,21)$ and translocation of DMIs influence disease control $(5,19)$. Some systemic DMIs accumulate around infection sites of various pathogens in wheat (7). The effects of infection by foliar diseases on host leaf physiology and metabolism are well documented $(11,12,17,22)$ but little is known about why fungicides should accumulate during the infection process. There are several possible hypotheses. First, the pathogen may block the transpiration stream, which would cause a build-up of active ingredient (a.i.) around the infection site; second, the fungicide may partition into fungal mycelium more readily than into host mesophyll, which would increase the concentration of a.i. in infected regions of host tissue; and third, infection by the pathogen may locally alter the host's physiological and metabolic processes, modifying transport processes.

Mycosphaerella graminicola (anamorph Septoria tritici) causes $S$. tritici blotch of wheat, a disease of worldwide economic importance (9). DMI fungicides are very effective for control of $M$. graminicola and are used extensively, with at least one application per year in most wheat crops in the United Kingdom (14).

Fluquinconazole is a new quinazoline-based DMI fungicide. Applied as a foliar spray, it possesses a broad spectrum of activity against Ascomycetes, Basidiomycetes, and Deutromycetes and is active against $M$. graminicola (16). Although there are no published data showing translocation of radiolabeled fluquinconazole, biological studies of fluquinconazole in apple leaves have demonstrated that it is translocated acropetally (16).

The objectives of this paper were to determine (i) the pattern of fluquinconazole translocation in wheat leaves; (ii) whether fluquinconazole movement was modified by $M$. graminicola infection; and (iii) whether effects on translocation could be related to the infection process of the isolates or to alterations of physiology or metabolism in host leaves.

Corresponding author: R. Metcalfe; E-mail address: Richard.Metcalfe@aguk.zeneca,com

Publication no. P-2000-1010-01R

(C) 2000 The American Phytopathological Society

\section{MATERIALS AND METHODS}

Fungicides. Two ${ }^{14} \mathrm{C}$-radiolabeled fungicides were used: prochloraz (purity greater than 99\%; AgrEvo Ltd., Saffron Walden) with a specific activity of $14.6 \mu \mathrm{Ci}$ per $\mathrm{mg}$; and fluquinconazole (purity greater than 99\%, AgrEvo Ltd.) with a specific activity of either 128 or $168 \mu \mathrm{Ci}$ per mg. All experimental solutions were diluted in $85 \%$ ( $\mathrm{vol} / \mathrm{vol}$ ) aqueous acetone and a phosphonate adjuvant Hostarex (1 g/liter; AgrEvo Ltd.) was added to make plant uptake similar to commercial formulations.

Plant rearing. Wheat seedlings of $\mathrm{cv}$. Riband, with resistance to $M$. graminicola rated 3 on a scale in which 1 denotes high susceptibility and 9 complete resistance (1), were sown in pots $125 \mathrm{~mm}$ square and $100 \mathrm{~mm}$ deep filled with John Innes number two compost plus Osmocote (Scott's Europe BV, Heerlen, Netherlands) slow release fertilizer (containing N:P:K, 14:13:13). All plants were kept in a growth chamber, set to a 16-h photoperiod and a constant temperature of $20^{\circ} \mathrm{C}$. The relative humidity was between 80 and $90 \%$.

Inoculum. Two isolates of M. graminicola were used, selected in pilot experiments to be of roughly equal virulence, but from opposite ends of the flutriafol sensitivity spectrum. They were coded S (21.10.94-27, relatively triazole-susceptible) and R (5.10.94-51, relatively triazole-resistant) and chosen from a collection of field isolates sampled from Sonning and Jealotts Hill in the southeast of England (Berkshire, U.K.) between 1992 and 1994 (13). Each isolate was cultured from spores stored on silica gel and multiplied on potato dextrose agar. Spore suspensions for inoculation of plants were prepared in sterile distilled water.

In all experiments, the proportion of successful inoculations was measured at 22 days postinoculation (dpi) by counting the number of leaves with pycnidial lesions, either directly on the experimental plants or by assessing replicate sets of treated plants. The incidence of lesions was analyzed by a generalized linear model with a binomial link function and a logistic transformation of incidence in Genstat (NAG, Oxford, U.K.).

Tracing ${ }^{14} \mathrm{C}$ fungicide movement using combustion analysis. Single 1- $\mu$ l droplets of labeled prochloraz ( $0.4 \mathrm{~g}$ of a.i. per liter) or fluquinconazole ( $0.15 \mathrm{~g}$ of a.i. per liter) were applied to the mid- 
dle of the adaxial surfaces of second leaves at GS 12 or GS 13, using a microapplicator (Burkhard, Uxbridge, Middlesex, U.K.) fitted with a 50- $\mu$ l Hamilton syringe. Prochloraz solutions were prepared with $0.15 \mathrm{~g}$ of a.i. per liter of ${ }^{14} \mathrm{C}$-labeled compound plus $0.25 \mathrm{~g}$ of a.i. per liter of unlabeled prochloraz. Fluquinconazole solutions were prepared with pure unlabeled a.i. with a negligible volume of radiolabeled fungicide of very high specific activity added to obtain the required activity. Sites of application were marked with small dots of permanent ink at the edge of leaves. Once dry, all plants were returned to the growth room and positioned in a randomized block design with five replicated plants per treatment for each sampling. To allow quantitative assessment of fungicide application similar size droplets of each fungicide solution were dispensed onto six small sections of Parafilm and six 2-cm leaf sections before and after application of the experimental treatments.

Surface deposits of fungicide were removed from application sites using cellulose acetate stripping as described by Silcox and Holloway (20). Once dry, each acetate strip was removed, placed in a glass scintillation vial and dissolved in $20 \mathrm{ml}$ of scintillation fluid (Dioxan). The Parafilm sections were treated in the same way. Radioactivity was measured with an Intertechnique SL30 Liquid Scintillation Spectrometer (rebuilt, computer controlled and equipped with software by Lab Logic, Sheffield, U.K.). Each leaf was cut into $2-\mathrm{cm}$ sections with the center of each section ranging from $4 \mathrm{~cm}$ below the site of application to the leaf tips. The radioactivity of each section was quantified by wet combustion analysis with a 387 Oxidizer fitted with an Oximate 80 Robot (Packard, Pangbourne, Berkshire, U.K.). The radioactive $\mathrm{CO}_{2}$ was trapped in Carbosorbe and the scintillation fluid used was Permafluor. The leaf sections used to quantify the amount of radiolabeled material dispensed at the time of treatment application were assessed in the same way.

Distribution of fungicide within the leaf. Droplets of either prochloraz or fluquinconazole at $830 \mathrm{~Bq} / \mu \mathrm{l}$ were applied as above. Leaves were removed at $1,2,5,7$, and 9 days posttreatment (dpt).

Modification of distribution by fungal infection. Leaves of four replicate plants were inoculated at GS 13 with a 2- $\mu$ d droplet (200 spores per $\mu \mathrm{l}$ ) of one of the isolates or of sterile distilled water with an automatic pipette (EDP Plus, Rainin Instruments Co. Inc.) fitted with a $10-\mu$ lip. The site of inoculation was marked with a small spot of permanent ink at the edge of the leaf. Fluquinconazole droplets at $830 \mathrm{~Bq} / \mu \mathrm{l}$ were then applied in the middle of the leaf, $30 \mathrm{~mm}$ proximal to the site of inoculation. Leaves inoculated, but not fungicide treated, were used to estimate the

TABLE 1. Incidence of Mycosphaerella graminicola infection on cv. Riband wheat seedling leaves inoculated with one of two isolates and treated with water or ${ }^{14} \mathrm{C}$-labeled fluquinconazole (FQ) at GS 13

\begin{tabular}{|c|c|c|c|c|}
\hline \multirow[b]{2}{*}{ Treatment } & \multirow[b]{2}{*}{ Dose $^{a}$} & \multicolumn{2}{|c|}{$\%$ Incidence of lesions at $22 \mathrm{dpi}$} & \multirow[b]{2}{*}{ Sample size ${ }^{\mathrm{b}}$} \\
\hline & & Susceptible & Resistant & \\
\hline \multicolumn{5}{|c|}{ Combustion analysis } \\
\hline Water & 0 & 57 & 70 & 30 \\
\hline FQ & 0.15 & 25 & 60 & 20 \\
\hline \multicolumn{5}{|l|}{ RITA $1^{\mathrm{c}}$} \\
\hline FQ & 0.3 & 10 & 40 & 20 \\
\hline \multicolumn{5}{|l|}{ RITA 2} \\
\hline Water & 0 & 67 & 87 & 30 \\
\hline FQ 0 dpi & 0.3 & 20 & 80 & 20 \\
\hline FQ 7 dpi & 0.3 & 10 & 50 & 20 \\
\hline \multicolumn{5}{|l|}{ Microscopy } \\
\hline Water & 0 & 60 & 90 & 10 \\
\hline $\mathrm{FQ}^{\mathrm{d}}$ & 0.3 & 20 & 50 & 10 \\
\hline
\end{tabular}

${ }^{\text {a }}$ Fungicide dose measured in grams of active ingredient per liter.

b Number of leaves inoculated with each isolate.

c Radio thin-layer-chromatography.

${ }^{\mathrm{d}}$ Unlabeled fluquinconazole formulation. success of infection. After the leaves had dried all of the plants were covered with polythene bags for 3 days to increase humidity and enhance infection.

Assessments were done at 1, 4, 7, 13, and 18 dpt. Leaf sections $2-\mathrm{cm}$ long were cut around the inoculation site to ensure the region of infection was included in a single section. This resulted in the fungicide application site being split between the two lower leaf sections. The amounts of ${ }^{14} \mathrm{C}$ fluquinconazole at each position along a leaf, calculated as the logit-transformed percentage of the fluquinconazole applied, were compared for each treatment using analysis of variance in Genstat 5 version 3.1 (NAG Ltd., Oxford).

Tracing ${ }^{14} \mathrm{C}$ fluquinconazole movement with a radio thinlayer-chromatographic analyzer. Fluquinconazole drops at $0.3 \mathrm{~g}$ of a.i. per liter and approximately $1,900 \mathrm{~Bq} / \mu \mathrm{l}$ were applied as above. To make the rate of fluquinconazole uptake from the leaf surface more comparable to that from a commercial formulation the amount of Hostarex was reduced to $0.5 \mathrm{~g} / \mathrm{liter}$.

Two leaves from each treatment were detached at 1, 4, 6, 15, and $20 \mathrm{dpt}$ and the surface deposits of fluquinconazole were removed by acetate stripping and quantified as above. Both leaves were then stuck to the surface of a clean glass thin-layer chromatography (TLC) plate with double sided tape. Each plate was then fixed to the scanning bed of a radio TLC analyzer (RITA 3200) with the leaves perpendicular to the collimator head. The number of radioactive decays was measured for 5 min for each millimeter along each leaf, from the site of fluquinconazole application to the leaf tips. Presence or absence of a peak of ${ }^{14} \mathrm{C}$ fluquinconazole activity around the inoculation site was determined visually. The number of leaves with peaks in each inoculation treatment was compared by the chi-square statistic.

Light microscopy. To link fluquinconazole translocation to the progress of infection by $M$. graminicola, mycelial development was measured externally and internally over the same time scale as the radio-tracing experiments. Three $2-\mu$ drops of spore suspension were applied in a line across the middle of the leaf. Unlabeled 1- $\mu$ l fungicide droplets were applied $30 \mathrm{~mm}$ proximal or $30 \mathrm{~mm}$ distal to the inoculation site on the day of inoculation. Two replicate plants per pot and five replicate pots per treatment were used for each sampling date. Pots were arranged in a randomized block design.

At 7, 9, and 16 dpi, leaves were detached and placed in a clearing solution (3:1, vol/vol; ethanol/dichloromethane plus $1.5 \mathrm{~g}$ of trichloroacetic acid per liter) for 2 days. The cleared leaves were then transferred to fresh clearing solution and stored for up to 3 weeks. Leaves were then cut into $20-\mathrm{mm}$ sections and stained for $5 \mathrm{~min}$ in $1 \mathrm{vol}$ of $6 \mathrm{~g}$ of methanolic Coomassie brilliant blue-R (Sigma) per liter mixed with 1 vol of $150 \mathrm{~g}$ of aqueous trichloroacetic acid per liter. Leaves were rinsed in mounting solution (1:4:15, vol/vol, glacial acetic acid/glycerol/water), mounted on glass slides, and sealed with clear nail varnish.

The extent of surface and internal mycelial development was measured at 7 and $9 \mathrm{dpi}$, but only internal development was measured at 16 dpi. Surface development was assessed for each of the three inoculation sites on a leaf by measuring the length of the longest hypha that could be traced back to a single spore. At 7 and $9 \mathrm{dpi}$, there was little internal hyphal development, so the longest internal hyphae was measured at each inoculation site. At $16 \mathrm{dpi}$, the total distance of hyphal development distal and basipetal to the inoculation sites was measured for each treatment. The means from each treatment were compared by analysis of variance (ANOVA) in Genstat 5 version 3.1. Residual plots suggested that transformation of these data was not required.

Effect of relative timing of fungicide and inoculum application. Leaves were inoculated with three $1-\mu l$ droplets of a suspension of 100 spores per $\mu \mathrm{l}$ of $M$. graminicola across the width of each leaf. This was intended to maximize any effects that infection might have on fluquinconazole translocation. Fluquinconazole droplets at $0.3 \mathrm{~g} / \mathrm{liter}$ and $1,900 \mathrm{~Bq} / \mu \mathrm{l}$ were applied at the 
same time $30 \mathrm{~mm}$ distal or $30 \mathrm{~mm}$ proximal to the fungal inoculation, or, after a 7 day delay, $30 \mathrm{~mm}$ proximal to the inoculation. This time delay was based on published histopathological work $(3,9)$. Leaves were sampled at 1, 6, and $15 \mathrm{dpt}$. Leaves not analyzed immediately after sampling were sandwiched between blotting paper, pressed between heavy glass plates (10-mm thick) and stored in a fume cupboard for up to 4 weeks. On several occasions the number of leaves per plate was increased to a maximum of 12 . This reduced the clarity of the final output, but increased the number of replicates it was possible to analyze.

Transpiration and photosynthesis. An infrared gas analyzer (IRGA; LCA-3, Analytical Development Company (ADC) Ltd., U.K.) was used to measure rates of transpiration, stomatal conductance, and photosynthesis in host leaves treated with fluquinconazole and inoculated with each of the experimental isolates.

Leaves inoculated or left uninoculated had fungicide applied distally, proximally, or not at all, to make a $2 \times 3$ factorial design. Inoculation was made as before, with three 2- $\mu$ l drops of 100 spores per $\mu \mathrm{l}$ of spore suspension placed in a line across the middle of each treated leaf. Fluquinconazole was applied as $1-\mu 1$ drops of $0.3 \mathrm{~g} /$ liter with Hostarex, as before. Two replicate plants per pot and five replicate pots per treatment were used. Pots were arranged in a randomized block design.

Five leaves per treatment were measured at 1, 3, and 6 dpi. At 1 and $3 \mathrm{dpi}$, the region around the inoculation sites of leaves was measured on five replicate leaves per treatment. At 6 dpi a region between the inoculation site and leaf tip was also analyzed. At $17 \mathrm{dpi}$, some of the leaves had significant areas of senescence so only three leaves were analyzed per treatment. However, a further region proximal to the site of inoculation was included in the analysis.

Throughout all assessments, the reference air supply was taken from outside the growth room. This had a $\mathrm{CO}_{2}$ concentration of 330 to $340 \mu \mathrm{mol}$ of $\mathrm{CO}_{2}$ per mol of air. The relative humidity of the air entering the chamber was increased to $40 \%$ by bubbling the air through a dreschel bottle containing water. The same leaves were assessed on each occasion, and all measurements were taken at the same position in the growth room to ensure that all leaves were under similar lighting conditions (photosynthetically active photon flux density, $150 \mu \mathrm{mol} \mathrm{m} \mathrm{m}^{-2} \mathrm{~s}^{-1}$ ). Four replicate measurements for each region on each leaf were recorded at 5, 7, 9, and 10 min. Rates of transpiration, stomatal conductance, and photosynthesis were compared for all treatments and at all positions by ANOVA in Genstat 5 version 3.1. Residual plots suggested transformation of these data was not required.

\section{RESULTS}

Disease severity. In all experiments, high rates of infection (57 to $90 \%$ ) occurred in leaves not treated with fluquinconazole (Table 1). Lesions were produced by isolate $\mathrm{R}$ more often than isolate $\mathrm{S}$. Fluquinconazole reduced lesion formation significantly, and reduced lesion formation by isolate $\mathrm{S}$ significantly more than by isolate $\mathrm{R}$.

Combustion analysis. Fluquinconazole was translocated acropetally away from the site of application to the leaf tips. By $9 \mathrm{dpt}$, there was an even distribution of fluquinconazole along the length of each leaf (Figs. 1 and 2). In contrast, prochloraz was much more slowly translocated and the majority of the remaining label was still present at the application site at $10 \mathrm{dpt}$ (Fig. 1). There was some radioactivity in the $-2-\mathrm{cm}$ leaf sections. This was probably due to spreading of the fungicide formulations during application rather than basipetal translocation, because no fungicide ever reached the $-4-\mathrm{cm}$ sections, and the relative amount of fungicide at $-2 \mathrm{~cm}$ declined over time rather than increasing. There was no evidence that inoculation with either isolate of $M$. graminicola altered translocation of fluquinconazole (Fig. 2 and Table 2; factors: inoculation type, position and inoculation type, and position and dpi). The very large standard errors associated with the measurements at $-2,0$, and $2 \mathrm{~cm}$ at 1 and 3 dpi in Figure 2 are associated with slight errors in positioning, so that very high and low values occurred at each position, but if one position was high an adjacent position was low, etc. The ANOVA in Table 2 was done on square root transformed data to obtain a more satisfactory residual pattern and improve sensitivity to differences between inoculated and uninoculated leaves. The significant main effect of dpi is an artifact of the transformation, arising because the label became more evenly distributed over time; an analysis on untransformed data confirms that the total label on leaves did not change over the course of the experiment.

RITA. In uninoculated leaves, translocation of fluquinconazole was similar to that determined by combustion analysis (Fig. 3). However, in most distally inoculated leaves, peaks of ${ }^{14} \mathrm{C}$ fluquinconazole accumulation occurred at inoculation sites from $6 \mathrm{dpt}$ onward (Fig. 3A through C). Peaks were never seen in uninoculated leaves, and the difference in numbers of inoculated and uninoculated leaves with peaks was significant and consistent with the proportion of leaves subsequently developing lesions (Tables 3 and 4). However, there was no significant difference between the number of peaks that developed in leaves inoculated with either isolate or in leaves inoculated on the same day as or 7 days before fluquinconazole application. In leaves inoculated $30 \mathrm{~mm}$ proximal to sites of fluquinconazole application no peaks occurred at inoculation sites and there was no evidence of basipetal translocation (Fig. 3D).

Microscopy. At $7 \mathrm{dpi}$, there was extensive surface colonization by hyphae from both isolates of $M$. graminicola. Surface development increased substantially by 9 dpi (Table 5). At 9 dpi, hyphae were visibly penetrating stomata. Surface and internal hy-
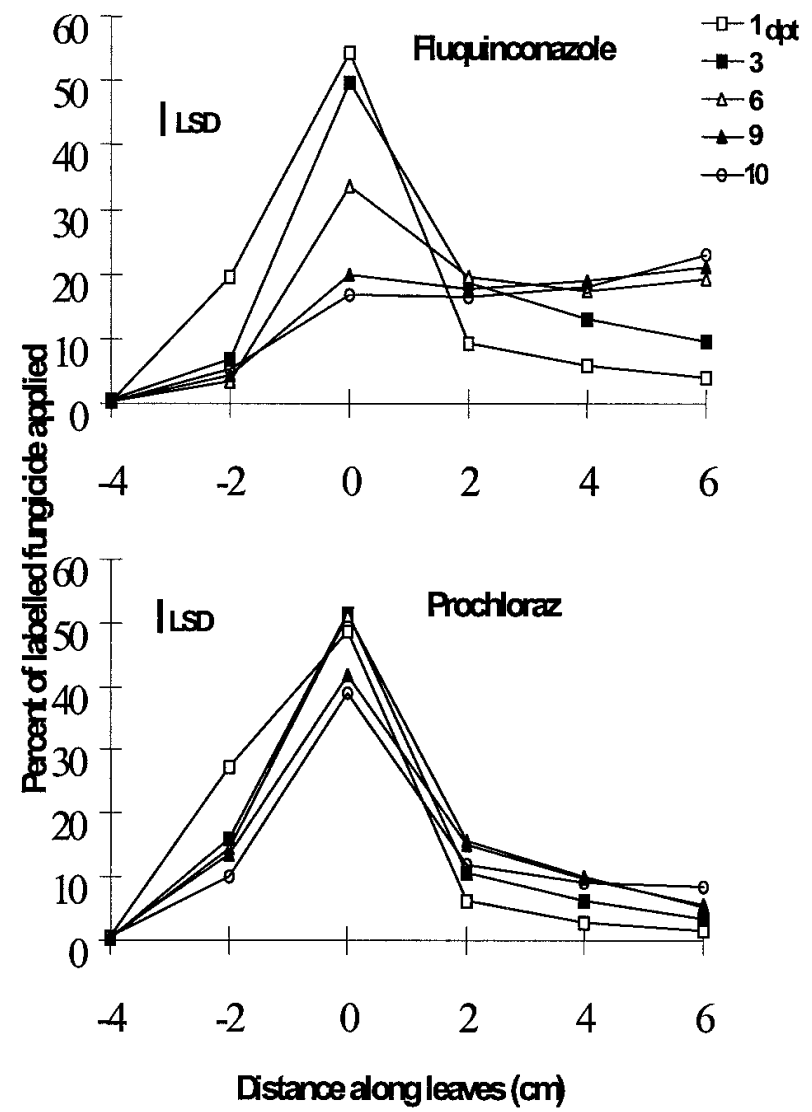

Fig. 1. Translocation of ${ }^{14} \mathrm{C}$-radiolabeled fungicides along seedling wheat leaves treated in the middle $(0 \mathrm{~cm})$ with single $1-\mu 1$ droplets of fluquinconazole and prochloraz at 1, 3, 6, 9, and 10 days post-treatment (dpt). Leaf tips were $6 \mathrm{~cm}$ above the site of application. A single least significant difference (LSD) bar is shown in each plot, but is valid for comparisons across plots. 
phae were significantly longer in the $\mathrm{R}$ isolate than in the $\mathrm{S}$ isolate at 7 and 9 dpi. By $16 \mathrm{dpi}$, pycnidial lesions were present on leaves treated with water and there was extensive internal mycelium in all of the leaves, though the mycelium of the resistant isolate extended along the leaves significantly further than the mycelium of the susceptible isolate (Table 5).

In leaves treated with fluquinconazole, the resistant isolate caused small pycnidial lesions ( 1 to $3 \mathrm{~mm}$ ), but the susceptible isolate only caused small areas of necrosis. Application of fluquinconazole significantly reduced the length of internal hyphae at 9 and 16 dpi. Although surface development by both isolates was reduced on leaves treated with fluquinconazole, the difference was not statistically significant.

Transpiration and photosynthesis. Rates of transpiration, stomatal conductance, and photosynthesis declined over time as the leaves aged. By 17 dpi leaf tips were senescent.

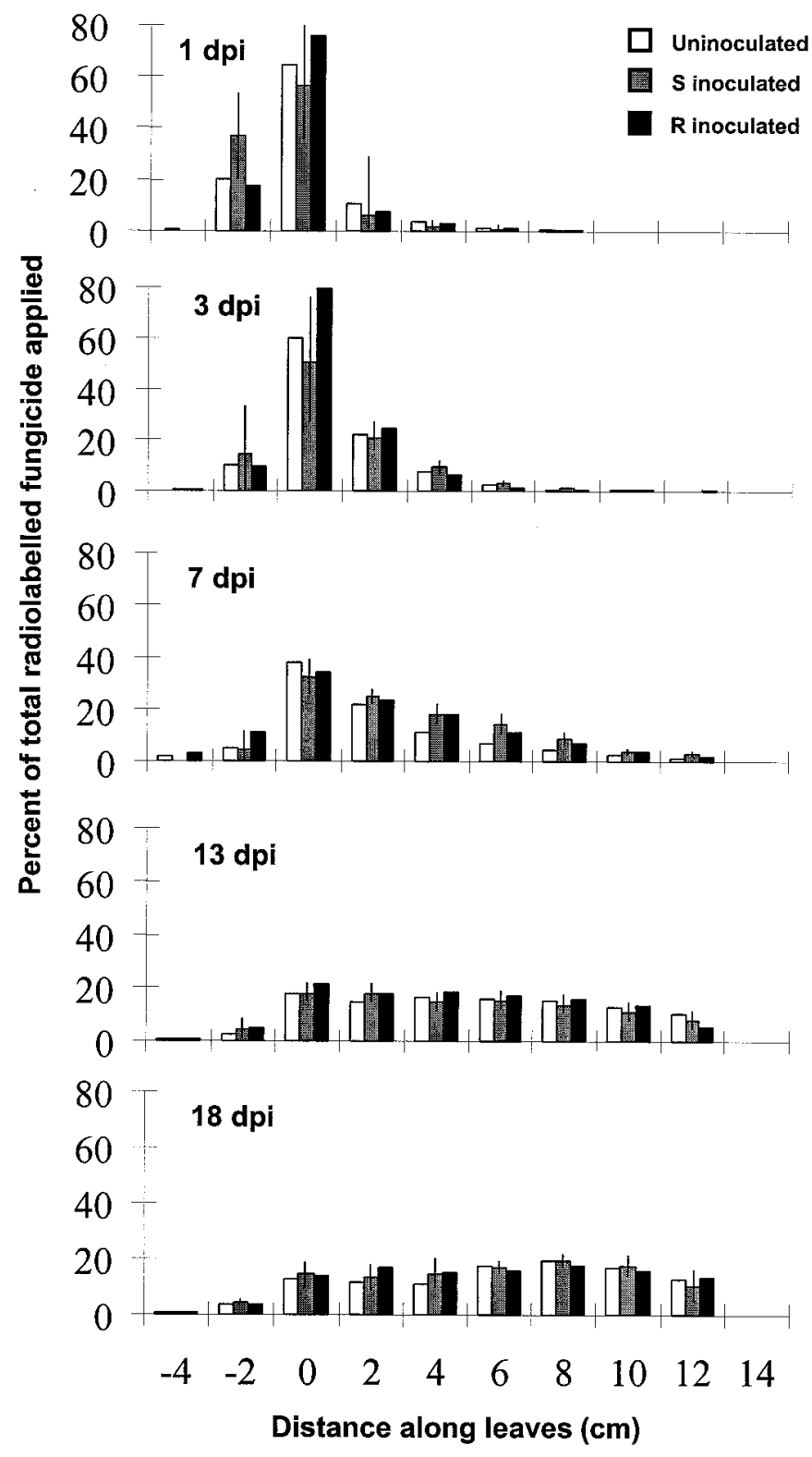

Fig. 2. Distribution of ${ }^{14} \mathrm{C}$-radiolabeled fungicides along seedling wheat leaves treated in the middle (between -2 to $0 \mathrm{~cm}$ ) with single $1-\mu 1$ droplets of fluquinconazole at $1,4,7,13$, and 18 days postinoculation and either uninoculated or inoculated with sensitive $(\mathrm{S})$ or resistant $(\mathrm{R})$ isolates of Mycosphaerella graminicola in the 2-cm section. Leaf tips were 12 to $14 \mathrm{~cm}$ above the site of application. Error bars are 2 standard errors of the mean either side of the mean, using the variance calculated for all leaf sections at that position and time.
Transpiration rates and stomatal conductance in inoculated leaves differed significantly from uninoculated leaves at 1,6 , and 17 dpi (Table 6). At 1 dpi, transpiration and stomatal conductance was significantly higher in inoculated leaves. At 6 dpi, averaged over both positions, transpiration and stomatal conductance was significantly higher in leaves inoculated with isolate $\mathrm{R}$ than in either uninoculated leaves or leaves inoculated with isolate $\mathrm{S}$. At $17 \mathrm{dpi}$, averaged over all positions, transpiration and stomatal conductance was higher in inoculated leaves than in uninoculated leaves, though this did vary with position around the inoculation site. Compared with uninoculated leaves, transpiration rates proximal to inoculation sites were significantly raised, but distally transpiration rates were only higher in leaves inoculated with isolate S. In leaves inoculated with isolate $\mathrm{R}$, stomatal conductance was significantly raised proximal to inoculation sites, but in leaves inoculated with isolate $\mathrm{S}$, stomatal conductance was raised at and distal to inoculation sites.

Photosynthesis rates varied significantly between treatments. At each assessment, rates of photosynthesis were significantly lower in leaves inoculated with isolate R (Table 6). At 6 dpi, photosynthesis was lower at and distal to inoculation sites. Averaged over distal and proximal positions, photosynthesis was significantly lower in inoculated leaves. At $17 \mathrm{dpi}$ in inoculated leaves, rates of photosynthesis were significantly greater proximal to the site of inoculation than distal to it, although photosynthesis did not differ significantly with position in uninoculated leaves.

\section{DISCUSSION}

Fluquinconazole was translocated acropetally, but not basipetally. In contrast, prochloraz was relatively immobile, consistent with other work on the mobility of fluquinconazole (16) and prochloraz $(3,5)$.

RITA demonstrated that infection by $M$. graminicola caused fluquinconazole to accumulate at the point of inoculation. However, this effect was not seen in combustion analysis of 20-mm leaf sections. This is probably because the peaks of fluquinconazole accumulation rose and fell within a few millimeters and combustion of $20-\mathrm{mm}$ sections was not sensitive enough to detect them. Accumulation could improve pathogen control by more effectively targeting the site of infection. It has been demonstrated with other DMI fungicides and pathogens, but is not universal. For example, Humphreys et al. (7) found that flutriafol accumulated around infection sites of Stagonospora nodorum and Erysiphe graminis in wheat, and diclobutrazole accumulated around infection sites of $S$. nodorum and Puccinia recondita in wheat, but hexaconazole did not accumulate around infection sites of any of these host-pathogen systems. Further work needs to be

TABLE 2. Analysis of variance of distribution of ${ }^{14} \mathrm{C}$-labeled fluquinconazole ${ }^{\mathrm{a}}$

\begin{tabular}{lrrrc}
\hline Factor & df & $\mathrm{MS}^{\mathrm{b}}$ & $F$ & $P$ \\
\hline Comparisons across leaves & & & & \\
$\quad$ Dpi & 4 & 21.1 & 73.7 & $<0.001$ \\
$\quad$ Inoculum & 2 & 0.64 & 2.2 & 0.12 \\
$\quad$ Inoculum and dpi & 8 & 0.3 & 1.1 & 0.75 \\
Residual in this stratum & 45 & 0.3 & & \\
Comparisons within leaves & & & & \\
$\quad$ Position (along leaf) & 8 & 128.5 & 170.0 & $<0.001$ \\
$\quad$ Inoculum and position & 16 & 0.8 & 1.1 & 0.36 \\
$\quad$ Position and dpi & 32 & 18.5 & 24.5 & $<0.001$ \\
$\quad$ Inoculum, position, and dpi & 64 & 0.9 & 1.2 & 0.13 \\
Residual & 360 & 0.8 & & \\
\hline
\end{tabular}

a Measured as a square root (percentage of total active ingredient applied found in each section) between $2-\mathrm{cm}$ sections of seedling wheat leaves cv. Riband at 1, 4, 7, 13, and 18 days postinoculation (dpi). Leaves were inoculated with one of two $M$. graminicola isolates or water, $30 \mathrm{~mm}$ distal to the site of fluquinconazole application.

${ }^{\mathrm{b}}$ MS indicates the value of the treatment mean square. 
done to determine whether multiple sites of accumulation develop in leaves inoculated at several different sites, and which fungicides show the effect. It is possible that accumulation is associated with particular modes of action or physicochemical properties, knowledge of which might help to improve the activity of new fungicide molecules.

We have evaluated three hypotheses concerning the cause of the accumulation. It is unlikely to result from mycelium physically constricting the transpiration stream. Previous work has shown that internal development of $M$. graminicola begins within 2 to 3 days of inoculation $(2,8,18)$, but the microscopic study showed that at 9 dpi only sparse internal hyphae were visible and none could be seen before this, whereas fluquinconazole accumulated around inoculation sites from 6 dpi. Our microscopic observations appear inconsistent with those of Cohen and Eyal (2) and Kema et al. (8), who were able to detect stomatal penetration occurring from 2 dpi on wheat leaves sprayed with $M$. graminicola isolates. However, we looked at single site inoculations by small numbers of spores, not leaves uniformly sprayed, in which one site of maximum colonization would be selected for study. The difference might alternatively be associated with the use of different host cultivars and M. graminicola isolates.

An alternative hypothesis is that fungicide was selectively partitioned into fungal hyphae. However, diclobutrazole mainly accumulated in host mesophyll and only slightly in fungal hyphae (7). Because the effect in our experiments occurred with so little
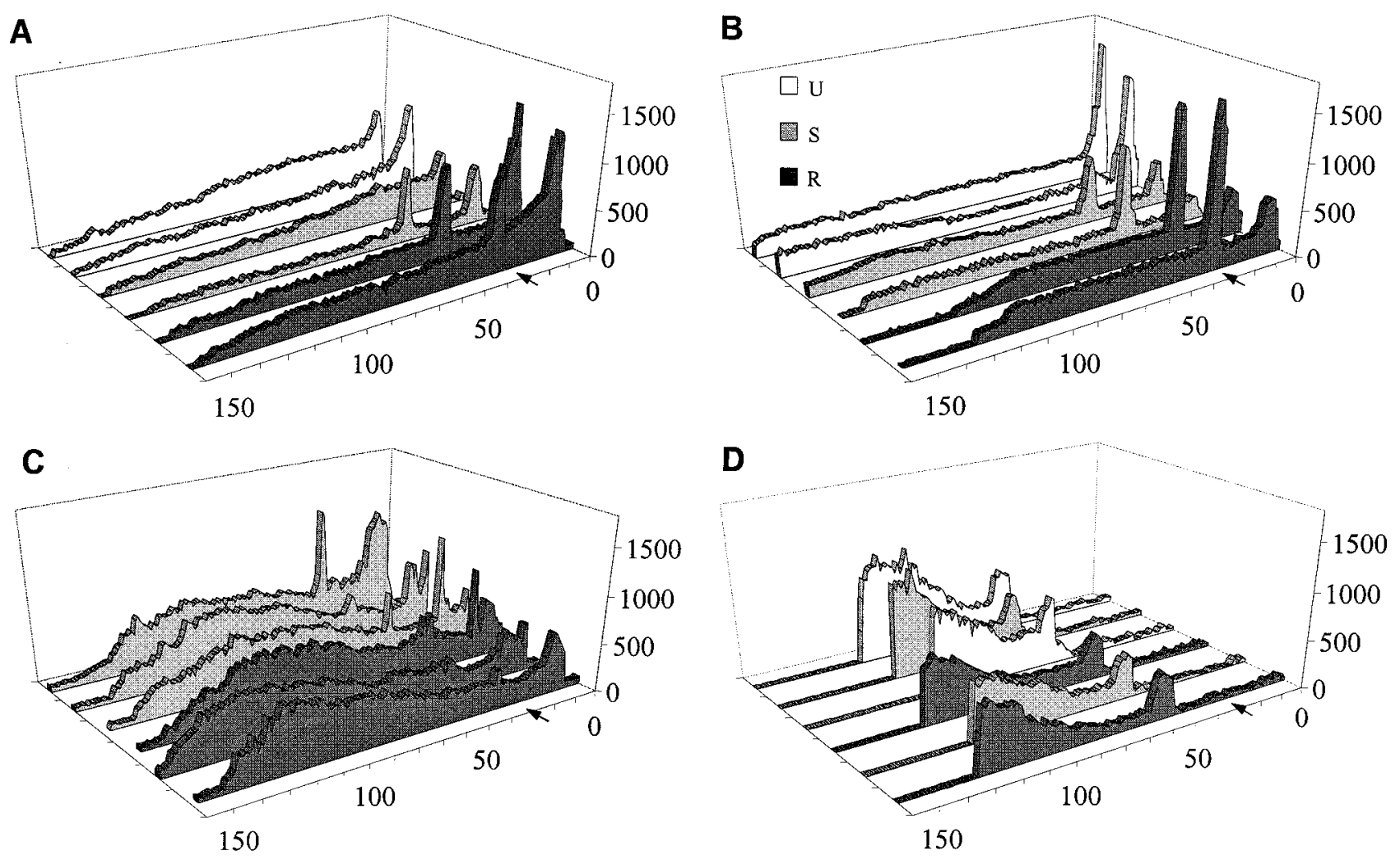

Distance along leaf $(\mathrm{mm})$

Fig. 3. Translocation of ${ }^{14} \mathrm{C}$ fluquinconazole (FQ) in seedling wheat leaves treated with a single $1-\mu 1$ droplet of fluquinconazole in the middle (A through C, at $0 \mathrm{~mm}$ and $\mathbf{D}$, at $55 \mathrm{~mm}$ ) and either uninoculated (U) or inoculated with fungicide susceptible (S) or resistant (R) isolates of Mycosphaerella graminicola. Leaves were inoculated either $30 \mathrm{~mm}$ below fungicide sites and sampled at A, 6 days post-treatment (dpt); B, $15 \mathrm{dpt}$; $\mathbf{C}, 20 \mathrm{dpt}$ or $30 \mathrm{~mm}$ above fungicide sites and sampled at $\mathbf{D}, 15 \mathrm{dpt}$. Inoculation sites are indicated by an arrow.

TABLE 3. Number of leaves with fluquinconazole (FQ) accumulation peaks at sites inoculated with Mycosphaerella graminicola or water at 1, 4, 6, 15, and 20 days post-treatment $(\mathrm{dpt})^{\mathrm{a}}$

\begin{tabular}{|c|c|c|c|c|c|c|c|c|}
\hline \multirow[b]{2}{*}{ Experiment } & \multicolumn{2}{|c|}{ Treatment } & \multicolumn{6}{|c|}{$\mathrm{dpt}^{\mathrm{b}}$} \\
\hline & Inoculum & FQ (dpi) & 1 & 4 & 6 & 15 & 20 & Total \\
\hline \multirow[t]{2}{*}{ RITA $1^{c}$} & Water & 0 & $0(2)$ & $0(2)$ & $0(2)$ & $0(2)$ & & $0(8)$ \\
\hline & $\mathrm{S}$ isolate & 0 & $0(2)$ & $0(2)$ & $1(2)$ & $2(2)$ & $2(3)$ & $5(11)$ \\
\hline \multirow[t]{4}{*}{ RITA 2} & Water & 0 & $0(7)$ & $\ldots$ & $0(15)$ & $0(10)$ & $\ldots$ & $0(32)$ \\
\hline & & 7 & $0(4)$ & $\ldots$ & $0(8)$ & $0(6)$ & $\ldots$ & $0(18)$ \\
\hline & $\mathrm{S}$ isolate & 0 & $0(8)$ & $\ldots$ & $8(11)$ & $6(10)$ & $\ldots$ & $14(29)$ \\
\hline & & 7 & $0(4)$ & $\ldots$ & $4(8)$ & $7(10)$ & $\ldots$ & $11(22)$ \\
\hline
\end{tabular}

${ }^{a}$ Seedling wheat leaves were treated in the middle with $1-\mu l$ droplets of water or FQ, either on the same day as inoculation $(0$ dpi) or 7 days postinoculation (7 dpi). Droplets of either sensitive (S) or resistant (R) isolates were applied $30 \mathrm{~mm}$ above the site of fungicide application.

$\mathrm{b}$ Number of replicate leaves in parentheses.

${ }^{\mathrm{c}}$ Radio thin-layer-chromatographic analysis. 
visible colonization, the affinity difference between plant and fungal tissue would have to be very large for this to explain the effect. If increased partitioning of fluquinconazole into fungal mycelium caused peaks, delaying application would allow more

TABLE 4. Comparison of number of accumulation peaks of ${ }^{14} \mathrm{C}$ fluquinconazole (FQ) in seedling wheat leaves at sites inoculated with fungicidesusceptible (S) or resistant ( $\mathrm{R}$ ) isolates of Mycosphaerella graminicola using chi-square $\left(\chi^{2}\right)$ analysis

\begin{tabular}{llcl}
\hline Data set $^{\mathrm{a}}$ & \multicolumn{1}{c}{ Comparison } & df & $\left(\chi^{2}\right)^{\mathrm{b}}$ \\
\hline RITA 1 & Uninoculated vs. all inoculated & 1 & $5.20^{* *}$ \\
RITA 2 & $\begin{array}{c}\text { Difference between uninoculated } \\
\text { and inoculated leaves }\end{array}$ & & \\
& Difference between isolates $^{\mathrm{d}}$ & 5 & $8.36^{* * *}$ \\
& Difference between FQ timing $^{\mathrm{e}}$ & 1 & $0.02 \mathrm{NS}$ \\
& & 1 & $0.10 \mathrm{NS}$ \\
\hline
\end{tabular}

${ }^{a}$ Radio thin-layer-chromatographic analysis.

${ }^{\mathrm{b}} \mathrm{NS}=$ nonsignificant at $P=0.05 ; * *, P \leq 0.05$; and $* * *, P \leq 0.001$.

${ }^{c}$ Full data set with all treatments and inoculations included in contingency table.

${ }^{\mathrm{d}}$ Data from leaves inoculated with $\mathrm{S}$ and $\mathrm{R}$ isolates compared in contingency table. Data from FQ application at 0 and 7 dpi was combined and uninoculated leaf data was omitted.

${ }^{\text {e }}$ Data from leaves treated with FQ at 0 and 7 dpi compared in contingency table. Data from leaves inoculated with $\mathrm{S}$ and $\mathrm{R}$ isolates was combined and uninoculated leaf data was omitted. time for colonization and increase the frequency of peaks. However, peaks were seen equally when fluquinconazole was applied at 0 and $7 \mathrm{dpi}$, while control of both isolates was better at $7 \mathrm{dpi}$. This is not a conclusive test because colonization was so sparse at $7 \mathrm{dpi}$ and a test later during colonization might be more conclusive.

A third hypothesis is that the accumulation was caused by a host response to infection. In this case, it follows that the host must react to the infection before extensive hyphal extension within the leaf occurs (between 7 and 9 dpi). Changes in physiology did occur. Furthermore, although isolate R colonized the host more than isolate $\mathrm{S}$, there was no difference between isolates in the number of leaves showing ${ }^{14} \mathrm{C}$ fluquinconazole accumulation sites. Both arguments support the hypothesis that accumulation was due to a host response.

It is well documented that disease infection alters host physiological and metabolic processes $(11,12,17,22)$, so alteration of leaf transpiration around the infection site could cause accumulation of xylem mobile fungicides. However, there was no consistent pattern of change in transpiration or other measured physiological properties that would clearly cause accumulation of fluquinconazole at infection sites.

In all experiments, isolate $\mathrm{R}$ was controlled less effectively than isolate $\mathrm{S}$, but there was no difference in the incidence of accumu-

TABLE 5. Radius of maximum detectable external and internal development (millimeters) of Mycosphaerella graminicola mycelium in seedling wheat leaves treated in the middle with water or fluquinconazole $(\mathrm{FQ})^{\mathrm{a}}$

\begin{tabular}{|c|c|c|c|c|c|c|c|c|c|}
\hline \multirow[b]{2}{*}{ Location and Treatment } & \multicolumn{3}{|c|}{$7 \mathrm{dpi}$} & \multicolumn{3}{|c|}{9 dpi } & \multicolumn{3}{|c|}{$16 \mathrm{dpi}$} \\
\hline & Isolate $\mathrm{R}$ & Isolate $\mathrm{S}$ & Mean & Isolate $\mathrm{R}$ & Isolate $\mathrm{S}$ & Mean & Isolate $\mathrm{R}$ & Isolate $\mathrm{S}$ & Mean \\
\hline \multicolumn{10}{|l|}{ External } \\
\hline Water & 2.27 & 1.42 & 1.84 & 5.94 & 4.01 & 4.97 & $\ldots$ & $\ldots$ & $\ldots$ \\
\hline Mean $^{b}$ & 2.25 & $1.29 * * *$ & $\ldots$ & 5.62 & $3.77 * * *$ & $\ldots$ & $\ldots$ & $\ldots$ & $\cdots$ \\
\hline \multicolumn{10}{|l|}{ Internal } \\
\hline Water & $\ldots$ & $\ldots$ & $\ldots$ & 1.11 & 0.54 & 0.82 & 11.11 & 8.85 & 9.98 \\
\hline
\end{tabular}

$\bar{a}$ Three 1- $\mu$ l droplets of either sensitive $(\mathrm{S})$ or resistant $(\mathrm{R})$ isolates were applied $30 \mathrm{~mm}$ above the site of fungicide application. Interactions that were not significant are not shown. Significant differences are indicated as: nonsignificant (NS); $P \leq 0.05(*) ; P \leq 0.01(* *)$; and $P \leq 0.001(* * *)$. Dpi $=$ days postinoculation. Mean within rows compares treatments over isolates.

${ }^{\mathrm{b}}$ Within columns, comparing isolates averaged over treatments.

${ }^{\mathrm{c}}$ Means of three sites per leaf from six leaves.

TABLE 6. Rates of transpiration ( $\mathrm{mmol} \mathrm{m} \mathrm{m}^{-2} \mathrm{~s}^{-1}$ ), stomatal conductance $\left(\mathrm{mol} \mathrm{m}^{-2} \mathrm{~s}^{-1}\right)$, and photosynthesis $\left(\mu \mathrm{mol} \mathrm{m} \mathrm{m}^{-2} \mathrm{~s}^{-1}\right)$ at 2 -cm sections along leaves treated with fluquinconazole and inoculated with either susceptible or resistant isolates of Mycosphaerella graminicola or uninoculated ${ }^{\mathrm{a}}$

\begin{tabular}{|c|c|c|c|c|c|c|c|c|c|}
\hline \multirow[b]{3}{*}{ Inoculum } & \multirow{3}{*}{$\begin{array}{c}1 \\
\text { Site }\end{array}$} & \multirow{3}{*}{$\begin{array}{c}3 \\
\text { Site } \\
\end{array}$} & \multicolumn{7}{|c|}{ Assessment time (dpi) and position ${ }^{\mathrm{b}}$} \\
\hline & & & \multicolumn{3}{|c|}{6} & \multicolumn{4}{|c|}{17} \\
\hline & & & Site & Above & Mean & Below & Site & Above & Mean \\
\hline Uninoculated & 6.31 & 5.15 & 4.86 & 4.62 & 4.72 & 3.49 & 3.76 & 3.51 & 3.59 \\
\hline Susceptible & 7.38 & 5.15 & 4.82 & 4.77 & 4.79 & 4.34 & 5.12 & 4.95 & 4.80 \\
\hline Resistant & 7.68 & 5.04 & 5.08 & 4.90 & 4.99 & 5.73 & 3.85 & 3.83 & 4.47 \\
\hline Uninoculated & 0.97 & 0.77 & 0.85 & 0.73 & 0.79 & 0.58 & 0.54 & 0.47 & 0.53 \\
\hline Susceptible & 1.79 & 0.74 & 0.81 & 0.76 & 0.78 & 0.70 & 1.06 & 0.96 & 0.90 \\
\hline Resistant & 2.11 & 0.74 & 0.91 & 0.82 & 0.86 & 1.83 & 0.49 & 0.53 & 0.95 \\
\hline LSD & 0.25 & NS & $N S^{d}$ & & 0.36 & & 0.45 & 0.26 & \\
\hline \multicolumn{10}{|l|}{ Photosynthesis } \\
\hline Uninoculated & 3.93 & 4.42 & 4.41 & 3.65 & 4.03 & 1.90 & 2.46 & 1.63 & 2.00 \\
\hline
\end{tabular}

a Leaves were treated with single droplets of fluquinconazole in the middle of each leaf.

${ }^{\mathrm{b}}$ Position was $30 \mathrm{~mm}$ distal to (above) or promimal to (below) site of inoculation and dpi $=$ days postinoculation.

${ }^{\mathrm{c}}$ Least significant difference values $(P \leq 0.05)$ are shown for the effect of inoculation averaged over measurement sites (given at the base of the 'mean' columns) and for the interaction between inoculation type and position of measurements at 6 and $17 \mathrm{dpi}$ (given at the bottom mid dle of each data set).

${ }^{\mathrm{d}}$ Interaction was not significant. 
lation peaks with either isolate. Any difference in the two isolates' response to fluquinconazole was therefore probably not connected with avoidance of high levels of fungicide in host tissue. However, to be sure that the amount of fluquinconazole accumulating at infection sites was not different for each isolate, quantitative analysis of very small leaf sections (of the order of a few millimeters) would be required. Fluquinconazole reduced development of hyphae of both isolates similarly, but lesion production by isolate $\mathrm{S}$ was much more inhibited. This suggests that pycnidial formation and lesion development was the stage most sensitive to fluquinconazole in isolate $\mathrm{S}$.

In summary, we have shown that the mobile systemic fungicide fluquinconazole accumulates on a very small scale around sites of infection by $M$. graminicola. The accumulation is an indirect effect of host changes in response to infection starting very early in the infection process, well before the infection is securely established (18).

\section{ACKNOWLEDGMENTS}

This research was supported by the Biotechnology and Biological Sciences Research Council and AgrEvo U.K. Ltd. We thank A. Daniels, A. Deas, E. Barker, and R. Harris for their help with microscopy, RITA, IRGA, and combustion analysis, respectively.

\section{LITERATURE CITED}

1. Anonymous. 1997. Cereals variety handbook: NIAB recommended lists of cereals, 1997. Natl. Inst. Agric. Bot., Cambridge, U.K.

2. Cohen, L., and Eyal, Z. 1993. The histology of the processes associated with the infection of resistant and susceptible wheat cultivars with Septoria tritici. Plant Pathol. 42:737-743.

3. Cooke, B. K., Pappas, A. C., Jordan, V. W. L., and Western, N. M. 1979. Translocation of benomyl, prochloraz, and pyocymidone in relation to control of Botrytis cinerea in strawberries. Pest. Sci. 10:467-472.

4. Fuhr, F., Paul, V., Steffens, W., and Scheinpflug, H. 1978. Translocation of $[14 \mathrm{C}]$ triadimefon in spring barley and its activity against Erysiphie graminis v hordei. Pflanzen. Nach. Bayer 31:116-131.

5. Gisi, U., Rimach, E., Binder, H., Altwegg, P., and Hugelshofer, U. 1986. Biological profile of SAN $619 \mathrm{~F}$ and related EBI-fungicides. Pages 857864 in: Proc. Br. Crop Prot. Conf. Pests Dis.

6. Heaney, S. P., Martin, T. J., and Smith, J. M. 1988. Practical approaches to managing anti-resistance strategies with DMI fungicides. Pages 10971106 in: Proc. Br. Crop Prot. Conf. Pests Dis.

7. Humphreys, S. P., Ayres, P. G., Shephard, M. C., and Baldwin, B. C. 1992. Effects of fungal infection sites on the distribution of fungicides. Pest. Sci. 34:185-186.

8. Kema, G. H. J., Yu, D., Rijkenberg, F. H. J., Shaw, M. W., and Baayen, R. P. 1996. Histology of the pathogenesis of Mycosphaerella graminicola in wheat. Phytopathology 86:777-786.

9. King, J. E., Cook, R. J., and Melville, S. C. 1983. A review of Septoria diseases of wheat and barley. Ann. App. Biol. 103:345-373.

10. Kuck, K. H., and Thielert, W. 1987. On the systemic properties of HWG 1608 , the active ingredient of the fungicides Folicur and Raxil. Pflanzen. Nach. Bayer 40:133-152.

11. Owera, S. A. P., Farrar, J. F., and Whitbread, R. 1981. Growth and photosynthesis of barley infected with brown rust. Physiol. Plant Pathol. 18:79-90.

12. Owera, S. A. P., Farrar, J. F., and Whitbread, R. 1983. Translocation from leaves of barley infected with brown rust. New Phytol. 94:111-123.

13. Pijls, C. F. N., and Shaw, M. W. 1997. Weak selection by field sprays for flutriafol resistance in Septoria tritici. Plant Pathol. 46:247-263.

14. Polley, R. W., and Thomas, M. R. 1991. Surveys of diseases of winter wheat in England and Wales, 1976-1988. Ann. Appl. Biol. 119:1-20.

15. Querou, R., Euvard, M., and Gauvrit, C. 1998. Uptake and fate of triticiconazole applied as seed treatment to spring wheat (Triticum aestivum L.). Pest. Sci. 53:324-332.

16. Russell, P. E., Percival, A., Coltman, P. M., and Green, D. E. 1992. Fluquinconazole, a novel broad-spectrum fungicide for foliar application. Pages 411-418 in: Proc. Br. Crop Prot. Conf. Pests Dis.

17. Scholes, J. D. 1992. Photosynthesis: Cellular and tissue aspects in diseased leaves. Pages 85-106 in: Pests and Pathogens: Plant Responses to Foliar Attack. P. G. Ayres, ed. Bios Scientific Publishers, Oxford, U.K.

18. Shaw, M. W. 1991. Interacting effects of interrupted humid periods and light on infection of wheat leaves by Mycosphaerella graminicola (Septoria tritici). Plant Pathol. 40:595-607.

19. Shephard, M. C. 1985. Fungicide behavior in the plant: Systemicity Br. Crop Prot. Council Mono. 31:99-106.

20. Silcox, D., and Holloway, P. J. 1986. A simple method for the removal and assessment of foliar deposits of agrochemicals using cellulose acetate film stripping. Asp. Appl. Biol. 11:13-17.

21. Smith, C. M., Klapproth, M. C., Saunders, D. W., Johnson, L. E. B., and Trivellas, A. S. 1992. Biological properties of flusilazole contributing to its field performance. Pages 639-644 in: Proc. Br. Crop Prot. Conf. Pests Dis.

22. Wright, D. P., Baldwin, B. C., Shephard, M. C., and Scholes, J. D. 1995. Source sink relationships in wheat leaves infected with powdery mildew. I. Alterations in carbohydrate metabolism. Physiol. Mol. Plant Pathol. 47:237-253. 